\title{
Features of the development of xylorhizomes in a dwarf subshrub Scutellaria mongolica K. Sobol.
}

\author{
Alexandra A. Guseva ${ }^{1}$, and Vera A. Cheryomushkina \\ ${ }^{1}$ Central Siberian Botanical Garden SB RAS, 630090 Novosibirsk, Russia
}

\begin{abstract}
The development of individuals of the endemic Scutellaria mongolica in the shrubbed meadow steppe and steppe meadow in the Kemerovo region was studied. It was established that the species forms an implicit polycentric dwarf subshrub life form with xylorhizomes. In adulthood, individuals form a clump, which includes three variants of xylorhizomes, differing in the time of occurrence, the origin and type of formation shoots. In the young generative state, epigeogenic xylorhisomes of two variants develop, and in the mature generative state, hypoepigeogenic xylorhisomes develop. In different habitats, multivariance of the development of adult individuals is observed. On a plain habitats in a steppe meadow, xylorhizomes branch in the third year, they are short, very thickened, and their life expectancy reaches 16 years. On the steep slopes in the shrubbed meadow steppe, xylorhizomes branch in the first year of their occurrence, they are long, slightly thickened, and their life expectancy is from 4 to 8 years. It was shown that the difference in the formation of xylorhisomes is one of the mechanisms for the sustainable existence of the species in different ecologo-phytocenotic conditions.
\end{abstract}

\begin{abstract}
Adaptations of organisms to a variety of habitat conditions manifest at all levels of organization. At the body level, special attention is devoted to morphological rearrangements. Morphobiological diversity is found both in the ecologo-geographical series (within the range), and in one coenopopulation [1]. The Multivariance of the development of individuals is a widespread phenomenon in plants; it is one of the mechanisms contributing to the normal existence of the species in specific ecologophytocenotic conditions [2-8].

$S$. mongolica is an endemic of the Altai-Sayan botanico-geographical province. Individuals of $S$. mongolica grow on the sandy terraces of rivers, along the banks of ponds, wet meadows, swamp forests, pebbles, rocky and gravelly screes and rocks. It occurs in meadow communities and creates a colorful seasonal aspect $[9,10]$.

Two habitats of the species in the Kemerovo region were investigated. In both habitats, a shrubbed meadow steppe and a steppe meadow, the species forms one life form. It is a implicitly polycentric dwarf subshrub with xylorhizomes [11]. When describing the structure of individuals, the paper used approaches adopted in plant biomorphology [12].
\end{abstract}

* Corresponding author: guseva.sc@,list.ru 
In ontogenesis, individuals undergo the following phases of morphogenesis: primary shoot $(\mathrm{p}-\mathrm{j})$ - branched primary shoot ["main axis"] (im) - primary bush $(\mathrm{v}-\mathrm{g} 1)$ - clump (g2) - clone (g3 - ss).

Seedlings $(p)$ and juvenile individuals $(j)$ are the primary long shoot, the apical bud of which does not die in the winter. In the second year of life, plants go into an immature state (im). The primary shoot continues to grow monopodially and branches. One of the buds in the axils of the cotyledon leaves starts to grow. A lateral monocyclic long shoot with short metamers in the basal part is formed. The second annual growth of the primary shoot and the elongated part of the lateral shoot die off at the end of the growing season.

In the virginal state (v), a primary bush is formed. It consists of lateral dicyclic long branching shoots (BS) that develop on the remains of the primary shoot. Each year, in an acropetal sequence, two branching shoots develop on the primary shoot. At the end of each year, they die off to the first annual growth. At the end of the virginal state, two shoots, upper in position, functionally become formation shoots of the $n$-th order. Due to the contracting activity of the root, the primary shoot is gradually drawn into the soil. At the end of the virginal state, several metameres of the primary shoot are found underground.

At 9 years of age, individuals pass into a young generative state $\left(g_{l}\right)$, the bush consists of monocyclic formation shoots (FS) of two types:

1. FS type I - a generative monocyclic long orthotropic shoot with a shortened basal part (3-7 short metamers with scaly leaves).

2. FS type II - generative monocyclic long shoot with plagiotropic basal part.

On the basis of formation shoots of different types, two variants of epigeogenic xylorhizomes are formed in the bush.

1. Xylorhizomes I variant are formed on the basis of the basal parts of formation shoots type I (Fig.1 I). The first link in the xylorhizome of the first variant is a formation shoot norder formed in the virginal state. The upper short metamer is the renewal zone of FS type I. The upstream part of the shoot dies at the end of the growing season. Each year, in the renewal zone, one shoot formation is formed. Thus, an epigeogenic basisympodial nonbranching xylorhizomes I variant are formed from the basal parts of the FS I type of different orders. It is being pulled into the soil gradually due to the contracting activity of the main root.

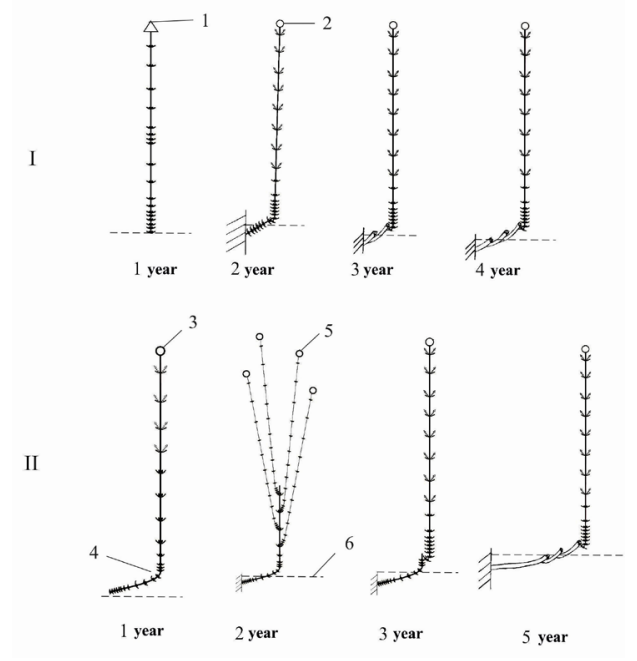

Fig. 1. The development of xylorhizomes I and II variant I - epigeogenic xylorhizome I variant; II epigeogenic xylorhizome II variant. 1 - dicyclic vegetative FS n-order, 2 - FS type I, 3 - FS type II, 4 - apogeotropic site, 5 - branch shoots (BS), 6 - soil level. 
2. The formation shoot type II, developing from dormant bud of the aerial part of the primary shoot is the first link of xylorhizome II variant (Fig. 1 II). In the first year, it blooms and dies to the middle part. The plagiotropic part, the apogeotropic region and the 4 lower long metameres are preserved. In the second year, the buds of four long metamers begin to grow, branching shoots develop. They are monocyclic long with a short basal part. By the third year, FS type II dies off untill to the apogeotropic zone. One of the dormant buds located here starts to grow, FS type I develops. The plagiotropic section of the FS type II and the basal parts of the sympodially growing formation shoots type I are gradually pulled into the soil, lignified, thicken and become the epigeogenic basisympodially growing xylorhizom II variant.

In the young generative state 2 epigeogenic xylorhisomes of the first variant and 1-3 epigeogenic xylorhisomes of the second variant develop in the bush. The annual growth of xylorhizomes is from 0.5 to $1 \mathrm{~cm}$.

In the mature generative state $\left(g_{2}\right)$ a clump forms. From the underground dormant buds located on the epigeogenic xylorhizomes of I and II variants, FS type III begin to develop. They are monocyclic generative with a long hypogeogenic site, which consists of long metamers with scaly leaves. (Fig. 2). In the second year the formation shoot branches out. Branching shoots are long with a short basal part. In the third year FS type I is formed from one of the aboveground buds of FS type III. Each year, one FS type I is formed in the innovation zone (the last short metamer in the basal part). Thus, hypo-epigeogenic xylorhizomes of the III variant is formed on the basis of the hypogeogenic site of the FS type III and the basal parts of the FS type I.

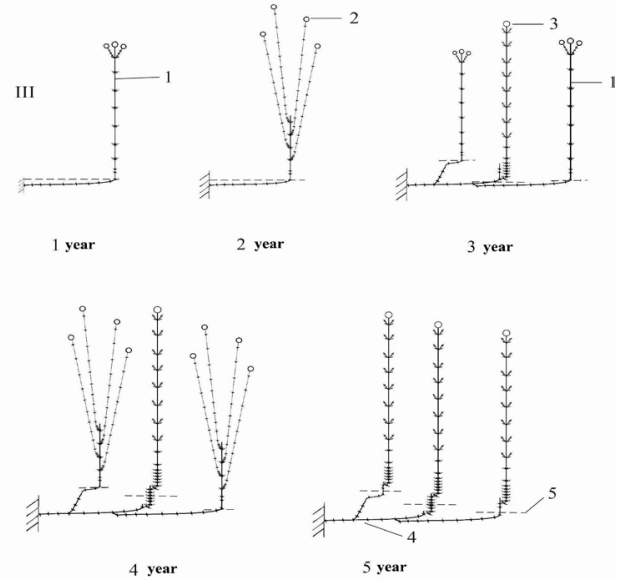

Fig. 2. The development of xylorhizomes III variant 1 - FS type III, 2 - BS, 3 - FS type I, 4 branched xylorhizome III variant, 5 -soil level. The adventitious roots are not indicated.

The hypogeogenic site of FS type III branches, new FS type III develop on it, due to this, the clump thrives significantly. In different habitats, multivariance of the development of mature individuals is observed which is manifested in the intensity of branching and the length of the hypo-epigeogenic xylorhizomes III variant (Fig. 3). On the plain habitats, xylorhizomes branch in the third year, they are much thickened and their life expectancy reaches 16 years. The diameter of the bushes does not exceed more than $30 \mathrm{~cm}$. On steep slopes, branching of xylorhizomes begins in the first year of their occurrence. Due to the increase in the length and strong branching of xylorhizomes, the clump diameter can reach $70 \mathrm{~cm}$. In contrast to plain habitats, xylorhizomes on the slopes are slightly thickened and their life expectancy is shorter (from 4 to 8 years). 

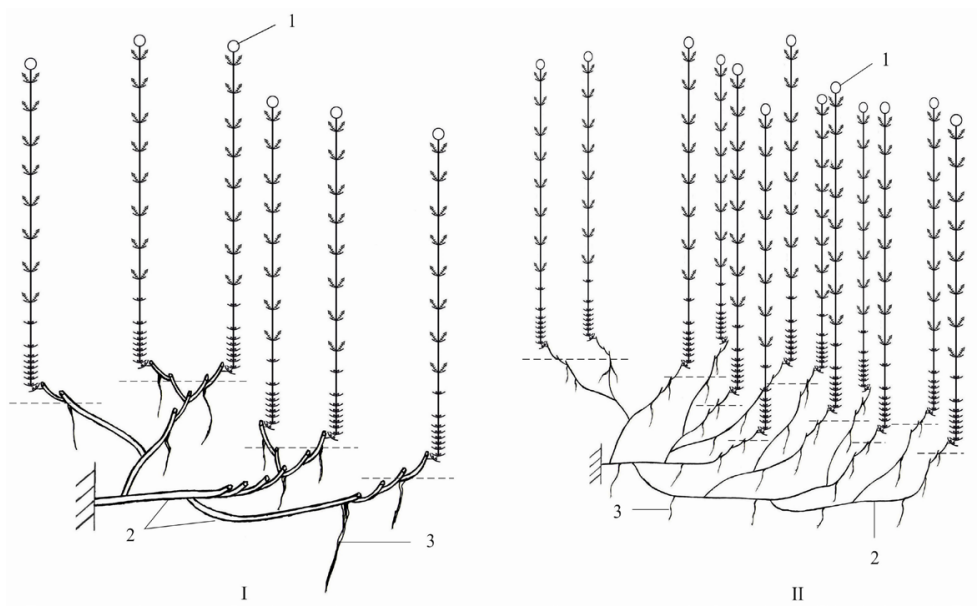

Fig. 3 Multivariance of xylorhizomes III variant of Scutellaria mongolica. I - plain habitats, II - steep slopes, 1 - formation shoot type I (generative monocyclic long orthotropic shoot with a short basal part), 2 - formation shoot type III (monocyclic generative with a long geophilic site), 3 -adventitious roots.

In the mature generative state, individuals are represented by clump consisting of a primary bush formed by xylorhizomes I variant and rooted partial bushes formed by xylorhizomes II and III variants. The root system is mixed. The adventitious roots developing on xylorhizomes gradually are thicken. Rooted partial bushes are formed. The retraction of the base of the primary and partial bushes into the soil continues due to the twisting of the main root and the contractile activity of the adventitious roots.

In the old generative state $\left(g_{3}\right)$, as a result of the decay of xylorhizomes, a particulation occurs. Separate partial bushes form. Xylorhizomes ceases to grow. Renewal in the bushes occurs due to underground dormant buds on xylorhizomes. In this state, and until the end of their life, individuals behave like herb polycarpics. The total life expectancy of individuals is $30-35$ years.

Thus, ontogenesis is complex, three variants of xylorhizomes develop in the structure of individuals. Two variants of epigeogenic xylorizomes develop in the young generative state. Hypo-epigeogenic xylorhisomes III variant develop in the mature generative state. The particulation occurs in the old generative state. In different habitats, the multivariance of development is manifested in individuals. The difference in their formation is one of the mechanisms contributing to the sustainable existence of the species in different ecologophytocenotic conditions.

The work was carried out with the financial support of the grant of RFBR within the framework of scientific project № 18-04-00621-a and project of the State Assignment of Central Siberian Botanical Garden of the Siberian Branch of the Russian Academy of Sciences № AAAA-A17-117012610053-9.

\section{References}

1. L. B. Zaugol'nova, Nauchnye dokl. vyshey shkoly. Biol. Nauki. 8, 65-72 (1974).

2. L. A. Zhukova, Russian J. Ecol. 32, 151-158 (2001).

3. S. N. Goroshkevich, E. A. Kustova, Russian J. Ecol. 33, 225-230 (2002).

4. V. A. Cheryomushkina, S. A. Sheremeteva, T. E. Buko, Bot. J., 93, 1565-1577 (2008).

5. A. Yu. Astashenkov, Contemp. Probl. Ecol. 8, 636-646 (2015). 
6. V. A. Cheryomushkina, A. A. Guseva, Contemp. Probl. Ecol. 8, 624-635 (2015).

7. M. N. Koldaeva, V. A. Kalinkina, Bull. MOIP. Otdel biol., 20, 40-46 (2015).

8. E. B. Talovskaya, Contemp. Probl. Ecol. 13, 266-273 (2020).

9. S. V. Yuzepchuk, Scutellaria L. Flora SSSR (AN SSSR, Moscow, Leningrad, 1954).

10. S. A. Sheremetova, A. L. Ebel', T. E. Buko, Tomsk State University Journal of Biology, 1, 52-72 (2012).

11. A. A. Guseva, Morphogenesis of species of the genus Scutellaria L. and the structure of their coenopopulations in Siberia (Novosibirsk, 2019)

12. I. G. Serebrjakov Ekologicheskaya morfologiya rasteniy (Moscow, 1962). 